\title{
Tyrosine-containing peptides are precursors of tyramine produced by Lactobacillus plantarum strain IR BL0076 isolated from wine
}

\author{
Maryse Bonnin-Jusserand, Cosette Grandvalet, Aurélie Rieu, Stéphanie Weidmann and Hervé Alexandre*
}

\begin{abstract}
Background: Biogenic amines are molecules with allergenic properties. They are found in fermented products and are synthesized by lactic acid bacteria through the decarboxylation of amino acids present in the food matrix. The concentration of biogenic amines in fermented foodstuffs is influenced by many environmental factors, and in particular, biogenic amine accumulation depends on the quantity of available precursors. Enological practices which lead to an enrichment in nitrogen compounds therefore favor biogenic amine production in wine. Free amino acids are the only known precursors for the synthesis of biogenic amines, and no direct link has previously been demonstrated between the use of peptides by lactic acid bacteria and biogenic amine synthesis.

Results: Here we demonstrate for the first time that a Lactobacillus plantarum strain isolated from a red wine can produce the biogenic amine tyramine from peptides containing tyrosine. In our conditions, most of the tyramine was produced during the late exponential growth phase, coinciding with the expression of the tyrDC and tyrP genes. The DNA sequences of tyrDC and tyrP in this strain share $98 \%$ identity with those in Lactobacillus brevis consistent with horizontal gene transfer from L. brevis to L. plantarum.
\end{abstract}

Conclusion: Peptides amino acids are precursors of biogenic amines for Lactobacillus plantarum strain IR BL0076.

Keywords: Tyramine, Peptides, Lactobacillus plantarum, Wine

\section{Background}

Biogenic amines (BA) are molecules found in a wide range of fermented foods and can present a health hazard, including food poisoning, following consumption $[1,2]$. The BA histamine and tyramine in particular cause hypertension and headaches [3]. BA in foods are mainly produced through the decarboxylation of amino acids (AA) by lactic acid bacteria (LAB) [4]. From a physiological point of view, BA production could help LAB to survive in acidic conditions by the production of metabolic energy [5]. Indeed the decarboxylation reaction from AA to BA, coupled to the transport, provides a proton motive force composed of a $\mathrm{pH}$ gradient (alkaline inside the cell) and a membrane electric potential (negative inside). This mechanism was described in Lactobacillus buchneri for histamine production by Molenaar

\footnotetext{
* Correspondence: rvalex@u-bourgogne.fr

AgrosupDijon, Valmis UMR PAM, Université de Bourgogne, Institut Universitaire de la Vigne et du Vin Jules Guyot, rue Claude Ladrey, BP 2787721078, Dijon Cedex, France
}

et al. [6], and more recently in Lactobacillus brevis for tyramine conversion from tyrosine by Wolken et al. [7]. Histamine [8], putrescine [9], tyramine [10] and cadaverine [11] are the main BA found in wine and are produced, during malolactic fermentation and storage, by LAB of various genera, notably Oenococcus, Lactobacillus, Leuconostoc and Pediococcus. The main producers of tyramine are species from the Lactobacillus genus [10]. Usually genes responsible for BA production are organized in clusters and are carried on genetic mobile elements integrated via horizontal gene transfer [12]. This explained the variability observed between strains for BA accumulation. Tyramine-producing bacteria carry a tyrDC cluster composed of four genes: tyrS encoding a tyrosil-tRNA synthetase, tyrDC encoding a decarboxylase, $\operatorname{tyr} P$ the tyrosine/tyramine transporter and $n h a C$ encoding an $\mathrm{Na}^{+} / \mathrm{H}^{+}$antiporter. This genetic organization has been described through LAB including Enterococcus faecalis [13], Lactococcus lactis [14] and Lactobacillus brevis [15].

\section{Biomed Central}


Several studies have investigated factors influencing $\mathrm{BA}$ production in wine. Low $\mathrm{pH}$ [8], high ethanol concentration and low concentrations of pyridoxal-5phosphate [16] favor reductions of BA accumulation. The BA content of wine also varies between viticultural regions, grape varieties [4,17] and vintages [18]. To avoid BA accumulation, commercially selected malolactic starters are added $[4,19]$ based on RAPD-PCR typing and selected for their technological performances to ensure MLF beginning and also wine quality [20]. One of the major factors affecting BA production is the concentration of amino acids or, more broadly, nitrogen compounds [1]. Free amino acids (AA) favor BA formation: the histidine and the tyrosine decarboxylases are both enzymes induced in Lactobacillus sp. by histidine [21] and in Lactobacillus brevis and Lactobacillus hilgardii by the addition of tyrosine [10]. The AA and biogenic amine contents of wine have been analyzed by HPLC to assess the relationships between the two classes of molecules $[22,23]$. When BA reached the detection threshold, a correlation was made between high amounts of AA and increased BA accumulation. Bach et al. [24] reported that the final concentration of BA increases if nitrogen compounds are added during alcoholic fermentation. Also, storage on lees [4] increases BA production due to the availability of nitrogen compounds released from yeasts undergoing autolysis. Yeast autolysis involves the breakdown of yeast cell membranes and the release of hydrolytic enzymes that then degrade components in the medium [25]; consequently, the medium is enriched in protein, peptides and free amino acids. Alexandre et al. [26] shown that yeasts can release until 40 mg. $\mathrm{L}^{-1}$ of peptides during autolysis. Furthermore wine peptides contain between 5 and $7 \mathrm{mg} . \mathrm{L}^{-1}$ of tyrosine [27] and contribute to the overall nitrogen compound [28]. So peptides, as well as free AA, could also be involved in BA production.

Moreover, LAB performing malolactic fermentation (MLF) express a proteolytic system; they therefore can degrade peptides in the extracellular or intracellular media and then decarboxylate AA to produce BA. Indeed, O. oeni exhibits a proteolytic activity against peptides in both white and red wines [29,30], and an extracellular protein, EprA, with protease activity has been characterized [31]. Nevertheless, it seems that the proteolytic activity of $\mathrm{O}$. oeni is dependent on both the composition of the medium and the bacterial growth phase [32]. A proteinase named PrtP produced by one isolate of Lactobacillus plantarum has been identified [33]. The aim of this study was to test the ability of $L$. plantarum to produce tyramine from synthetic peptides containing tyrosine, and to investigate whether peptides are hydrolyzed either inside the cell or in the extracellular medium.
Different sorts of synthetic peptides, containing two to four amino acids, were used to conduct these experiments depending on either the size or the place of the tyrosine residue. It is well known that transporters and intracellular peptidases have preferences for peptide size (for both). Indeed, various types of peptide transport have been described in the model LAB Lactococcus lactis. It harbors a well-characterized Opp transport system, of the $\mathrm{ABC}$ transporter family, which can transport peptides containing 4 to 35 residues [34]. The proteins DtpT and DppP are specialized in the transport of dipeptides [35] and tripeptides [36], respectively. L. plantarum has also an essential system for peptides uptake [37].

Peptidases display specificities for the position of residues in peptides. Many bacteria express specific intracellular peptidases able to hydrolyze peptide bonds. For example, the PepN aminopeptidase, has been described in a wide range of LAB including Lactobacillus helveticus [38], Lactobacillus delbrueckii [39] and Lactococcus lactis [40], and hydrolyze the residue located at the $\mathrm{N}$ terminus of peptides. Di- and tri-peptidases, such as PepV, isolated from Lactococcus lactis [41] and several lactobacilli, are able to breakdown dipeptides containing a Gly redisue at the N-terminus. In this study two of the peptides used (Gly-Leu-Tyr and Gly-Gly-Tyr-Arg) have a Gly residue at the N-terminus. Growth, tyramine production and expression of tyrDC and tyrP were also investigated in media with either free tyrosine or a mix of selected synthetic peptides.

\section{Results and discussion}

Lactobacillus plantarum is frequently isolated from red wine undergoing malolactic fermentation (MFL) and it usually contributes to production of tyramine [42]. It is auxotrophic for tyrosine and thus is suitable for studying the production of tyramine from peptides containing tyrosine.

\section{The tyrDC and tyrP genes of L. plantarum IR BL0076}

Based on 16S RNA gene sequencing [GenBank : JX025073] and multiplex PCR using recA gene-derived primers [43] (data not shown), a lactic acid bacterial strain isolated from wine and able to produce tyramine was identified as L. plantarum, and was named IR BL0076. To characterize the $t d c$ pathway of this strain, we amplified and sequenced the region carrying tyrDC and $\operatorname{tyr} P$; the complete sequences of the tyrDC and tyrP genes in Lactobacillus plantarum have not previously been reported although $\operatorname{tyr} D C$ was partially sequenced by Arena et al. [42]. The presence of the $\operatorname{tyr} D C$ gene is strain-specific, and sequenced L. plantarum genomes, like those of strains WCFS1 and ATCC 14917, do not carry the genes of the $\operatorname{tyr} D C$ pathway. 
Primers tyrSa and nhaCa were used to amplify the tyrDC and tyrP genes from L. plantarum IR BL0076; a fragment of the expected size $(3.8 \mathrm{kbp})$ was obtained and sequenced. The DNA sequence [GenBank : JQ040309] shares 98\% identity with those of the L. brevis NS77 tyrDC and tyrP genes. The deduced amino acid sequence showed 99 to $100 \%$ identity with TyrDC and TyrP from L. brevis NS77, IOEB 9809 and ATCC 367 strains (see Additional file 1). Regarding this alignment, the TyrDC sequence from L. brevis NS77 showed six amino acids substitutions compared to the three other strains: A63, N112, P184, S276, A564 and V572 are changed in E63, S112, Q184, R276, V564 and A572 respectively. Moreover the amino acid A564 is also changed in V564 for L. brevis ATCC 367. Lower identity was obtained with TyrDC from Lactobacillus brevis subsp. gravesensis (76\%). Identity with the sequences in other lactobacilli, such as Sporolactobacillus sp. Enterococcus hirae, Enterococcus faecium, Enterococcus durans and Enterococcus faecalis ranges between 66 and 80\%. Amino acid sequence similarity with the sequences from Lactobacillus coleohominis 101-4-CHN and Lactobacillus oris strains is lower, between 23 and $60 \%$, with better conservation for the TyrDC (60\% for both) than TyrP (55 and
$54 \%$ respectively) amino acid sequences. A phylogenetic tree was constructed to investigate the evolutionary relationships between these proteins. Based on the sequence divergence in amino acid TyrDC sequences (Figure 1), the phylogenetic tree reveals that L. plantarum TyrDC is closely related to those of $L$. brevis proteins and made one cluster clearly separated. Similar results were obtained when phylogenetic tree was constructed with TyrP amino acid sequences (data not shown). These results confirm that the organization of this L. plantarum $t d c$ locus is similar to those described for other LAB strains, with contiguous tyrDC and tyrP genes. The phylogenetic tree analysis is consistent with the $t d c$ locus of L. plantarum IR BL0076 strain having been transferred horizontally from $L$. brevis.

Growth of L. plantarum with peptides containing tyrosine Peptides of different sizes were used: a dipeptide Tyr-Ala containing the tyrosine residue at the $\mathrm{N}$-terminus, a tripeptide Gly-Leu-Tyr with the tyrosine at the C-terminus, and a peptide of four amino acids Gly-Gly-Tyr-Arg, where the tyrosine is in an internal position.

The growth was monitored by measuring the OD at $600 \mathrm{~nm}$. L. plantarum IR BL0076 was able to grow in

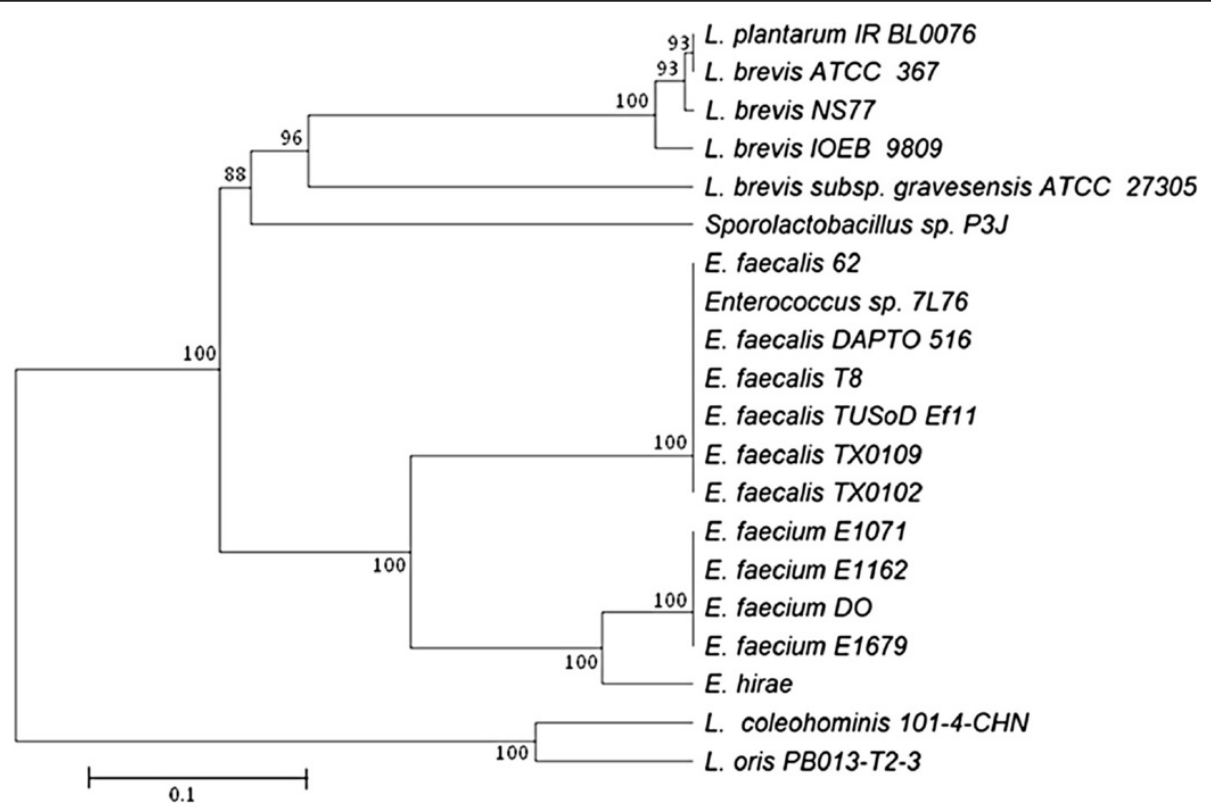

Figure 1 Phylogenetic tree comparing 21 TyrDC sequences from various Lactobacillus strains. The amino acid sequences were aligned using the multiple alignment program CLUSTAL W2. The phylogenetic tree was constructed by using the TreeTop from the GeneBee. Bootstrap values are expressed in percentages and indicated at nodes. The amino acid sequences of TyrDC were obtained from the following accession numbers entries: [GenBank: AF446085] (L. brevis IOEB 9809), [GenBank: YP_796294.1] (L. brevis ATCC 367), [GenBank: ABY71221.1] (L. brevis NS77), [GenBank: ZP_03940842.1] (L. brevis subsp. gravesensis ATCC 27305), [GenBank :AEB91325.1] (Sporolactobacillus sp. P3J), [GenBank : AAQ73505.1] (E. hirae), [GenBank : ZP_05553037] (L. coleohominis 101-4-CHN), [GenBank : ZP_07729457] (L. oris PBo13-T2-3), [GenBank :ZP_06679761] (E. faecium E1071), [GenBank : ZP_06677337] (E. faecium E1162), [GenBank : ZP_00602894.1] (E. faecium DO), [GenBank : ZP_06698865.1] (E. faecium E1679), [GenBank : CAF33980] (E. durans IPLA 655), [GenBank : ZP_05559869] (E. faecalis T8), [GenBank : ZP_07768147] (E. faecalis DAPTO 516), [GenBank: ZP_07771864] (E. faecalis TX0102), [GenBank : ZP_07569615] (E. faecalis TX0109), [GenBank : CBL32775] (Enterococcus sp. 7 L76), [GenBank : ADX79254] (E. faecalis 62) and [GenBank : ZP_04646316] (E. faecalis TUSoD Ef11). 
the synthetic medium either with free amino acids (medium 1) or synthetic peptides containing tyrosine (medium 2). The growth curve was the same in the two media (Figure 2), but not in MRS medium (control). Indeed at $28 \mathrm{~h}$ of growth, the maximum OD at $600 \mathrm{~nm}$ of 1,8 was reached in MRS rich medium, while in the synthetic poor media, the OD at $600 \mathrm{~nm}$ was 1,3. L. plantarum is auxotrophic for L-tyrosine [44], and indeed $L$. plantarum IR BL0076 could not grow in the synthetic medium used in this study without the inclusion of tyrosine. Therefore, the synthetic peptides in medium 2 were presumably metabolized even during the early stages of culture to release tyrosine and to allow the growth. This is consistent with the demonstration that two Lactobacillus strains (Lactobacillus homohiochii and Lactobacillus curvatus) isolated from sausages, express tyrosine and ornithine decarboxylase activities allowing growth at early stages of culture [45]; both strains display extracellular proteolytic activity which reaches a maximum in the early exponential growth. This activity is higher when the cells were grown in a peptide-rich medium. However, peptide transport and a subsequent intracellular hydrolysis is also plausible. Although LAB proteinases have a broad specificity and release oligopeptides in the range of 4 to $8 \mathrm{AA}$, intracellular peptidases are required for the complete degradation of peptides [46].

Tyramine production by lactobacillus plantarum IR BL0076 Supernatant harvested from the cultures after various times of growth was analyzed by HPLC to determine tyramine production (Figure 2). From Gomez-Alonso et al. [47], the detection limit for aminoenone derivative of tyramine is $0.02 \mathrm{mg} \cdot \mathrm{L}^{-1}$. Tyramine was identified by HPLC-MS (Table 1). At culture $\mathrm{OD}_{600 \mathrm{~nm}}=0.2$, no tyramine was detected in any culture. Tyramine was detected, at similar concentrations, in cultures in both media from $\mathrm{OD}_{600 \mathrm{~nm}}=1.0$. Concentrations of tyramine for both media were measured between 1.6 and $5.1 \mathrm{mg} . \mathrm{L}^{-1}$ (minimal and maximal measures respectively). The concentrations measured in both media are usually found in wine. Indeed in red wines, tyramine concentration can reached $28 \mathrm{mg} . \mathrm{L}^{-1}$ which is the upper limit, but most of time these concentrations are lower than 2.5 mg. $\mathrm{L}^{-1}$ [48]. Therefore, L. plantarum was able to synthesize tyramine similarly from free tyrosine and from peptides containing tyrosine.

Tyramine was produced throughout growth and it accumulated as the biomass increased. This is consistent with the biological role of tyramine: it is involved in energy production through decarboxylation coupled to transport [5]. This is the first demonstration that tyramine can be produced from peptides containing tyrosine and therefore that free tyrosine is not the only precursor for tyramine production. We studied the expression of the tyrDC and tyr $P$ genes to determine whether it was growth phasedependent and/or nitrogen source dependent.

\section{tyrDC and tyrP expression}

The tyrDC and tyrP genes are co-transcribed in E. faecalis [13], L. brevis [15] and Sporolactobacillus sp. [49]. A complete transcriptional analysis of the four genes of the operon was made in Lactobacillus brevis IOEB 9809 [15]. Even if tyrDC-tyrP transcripts were the most abundant, other polycistronic mRNA were described as: tyrS-

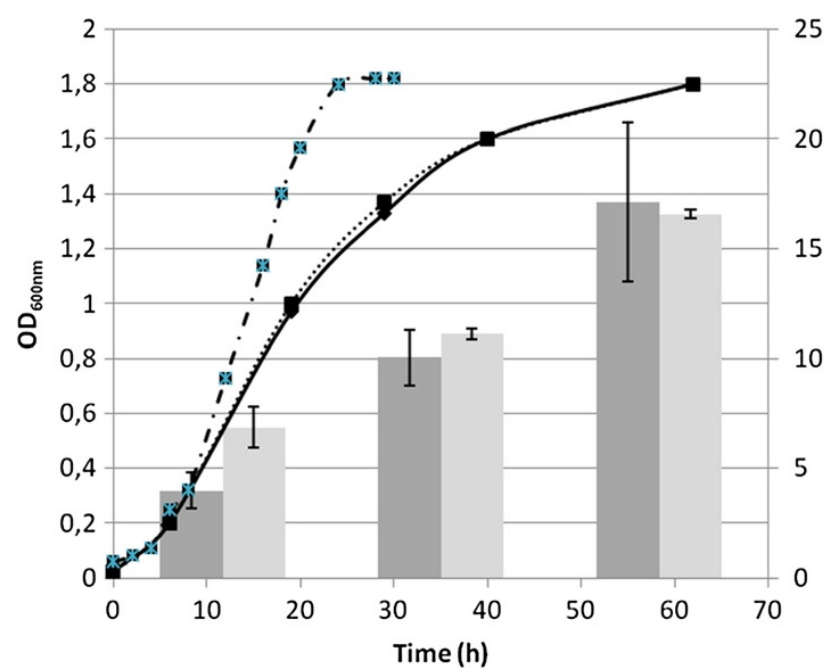

25

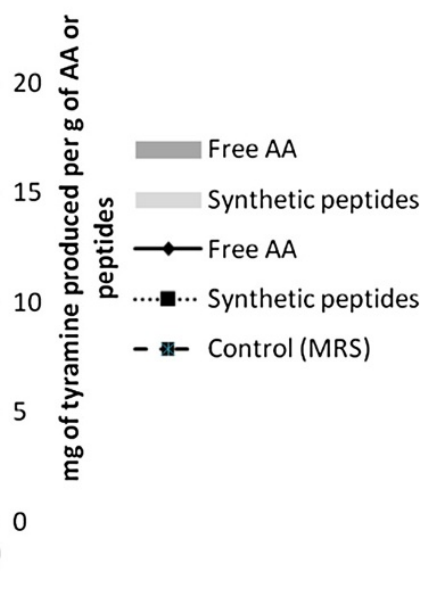

Figure 2 Influence of tyrosine or tyrosine containing peptides on growth and tyramine production by Lactobacillus plantarum IR BL0076. Lactobacillus plantarum IR BL0076 was grown in MRS medium (control curve; dashed line), synthetic medium with free tyrosine (continuous line) or in medium containing synthetic peptides as the sole tyrosine sources (dotted line). Tyramine was assayed by HPLC after various times of growth of L. plantarum IR BL0076 $\left(\mathrm{OD}_{600 \mathrm{~nm}}=1.0 ; 1.6 ; 1.8\right)$, in both culture media. Each value is the mean \pm SD of three independent experiments. 
Table 1 Identification of tyrosine and tyramine by HPLCMS

\begin{tabular}{lccc}
\hline Amine & Derivated mass & Molecular ion & Caracteristic ions \\
\hline Tyramine & 307 & 306 & $306,260,214,186$ \\
Tyrosine & 351 & 350 & $350,306,260$ \\
\hline
\end{tabular}

tyrDC-tyrP-nhaC and tyrS-tyrDC, as well as tyrP-nhaC. So tyrDC and tyrP can be transcribed from different manner. L. plantarum IR BL0076 tdc locus sequences was analysed using ARNold, an interface allowing localization of Rho-independent terminators in any bacterial sequence. (na.igmors.u-psud.fr/toolbox/arnold/). A predicted transcription terminator $(-11.70 \mathrm{kcal} / \mathrm{mol})$ localized at the $3 /$ end of TyrP coding region was identified. Erpin and RNAmotif programm predict the 5/ end position of this predicted transcription terminator at the nucleotide 3402 of the locus.

To check the presence of a bicistronic tyrDC-tyrP in the IR BL0076 isolate, we used Reverse-TranscriptionPCR experiments and primers tdcf and tyrPLpR located inside the $\operatorname{tyr} D C$ and $\operatorname{tyr} P$ genes respectively to study their expression in L. plantarum. An amplicon of 1,761 bp was obtained using cDNA obtained from RNA extracted from cultures on each medium 1 and medium 2 as the template. The length of the RT-PCR product indicates that tyrP is part of a polycistronic mRNA including $\operatorname{tyr} D C$. As the four genes of the tyrosine decarboxylase operon are part of a genetic island, as described for $L$. brevis [12], they have been disseminated through lactic acid bacteria via a horizontal gene transfer [49]. So it is expected that they are regulated in the same way in all enterococci and lactobacilli including L. plantarum.

To study the tyrosine transport, expression tyr $P$ and tyrDC was similarly analyzed by RT-qPCR. The expression of $\operatorname{tyr} P$ increased during growth in both medium 1 and medium 2, with a maximum at $\mathrm{OD}_{600 \mathrm{~nm}}=1.8$ (Figure 3a), and was significantly stronger during the stationary phase than during early exponential growth. The expression of tyrP paralleled the accumulation of tyramine in both media (Figure 1). This is coherent with what has been found for other bacteria producing biogenic amines, for example Streptococcus thermophilus [50], which produces histamine at the end of its growth, with an increase in the expression of the decarboxylase $h d c A$. The expression profile of $\operatorname{tyr} D C$ during growth was very similar to that of $\operatorname{tyr} P$ (Figure $3 \mathrm{~b}$ ). Both tyrDC and $\operatorname{tyr} P$ were significantly more strongly expressed during the early exponential growth phase in peptide medium (medium 2) than tyrosine medium (medium 1). Also, the expression of $\operatorname{tyr} D C$ during the stationary growth phase was higher in peptide than tyrosine medium. This higher expression in peptide medium was not associated with a higher concentration of tyramine, and its physiological significance is not clear. This is the first study of the influence of peptides on $\operatorname{tyr} D C$ and $t y r P$ expression in LAB.

\section{Proteolysis of peptides}

Tyramine could be produced from peptides in two ways. Peptides could be hydrolyzed in the extracellular medium by proteinase(s). Alternatively, they could be transported inside the cell by a peptide transporter, then hydrolyzed by intracellular peptidases, and the released tyrosine decarboxylated to give tyramine which could be exported by the TyrP permease. However, this second possibility is unlikely, because the TyrP transporter catalyses the exchange of tyrosine and tyramine. We assayed tyrosine in the culture medium during the growth of $L$. plantarum to determine whether peptides were hydrolyzed extracellularly (Figure 4).

In the peptide medium 2, the concentration of tyrosine was measured when the cultures reached the exponential growth phase. Therefore synthetic peptides were, as expected, hydrolyzed in the extracellular medium. Tyramine is presumably produced from the hydrolysis of peptides throughout the growth of the culture. The genome of the sequenced strain, L. plantarum WCFS1, contains genes encoding uptake systems for peptides, and in particular the oligopeptide transport system Opp. Once internalized, peptides can be degraded by peptidases. $L$. plantarum WCFS1 has nineteen genes encoding intracellular peptidases with diverse specificities [37]. Note also that one isolate of L. plantarum produces an extracellular proteinase, PrtP [33], and proteolytically active strains produce one or more other extracellular proteinase(s). Our experiments do not exclude the possibility that peptides are also imported and hydrolyzed inside the cell. Indeed, tyrosine generated by extracellular proteinase(s) could be exchanged with tyramine that has been formed inside the cell after decarboxylation of tyrosine derived from intracellular hydrolysis of peptides. However, no such mechanism has ever been described in any lactic acid bacteria.

\section{Conclusion}

This is the first demonstration that peptides containing amino acids precursors of biogenic amines (BA) can be used by bacteria to produce such BA. We show that peptides are, in fact, broken down into amino-acids (AA), which are the BA precursors in the extracellular medium. Peptide transport has a high energy cost for the cell and requires the hydrolysis of ATP [46]. This degradation of peptides outside the cell is thus a simple and energetically favorable way to obtain free AA for metabolic needs.

This study is of technological interest, because most enological practices aim at enriching wine in nutrients 


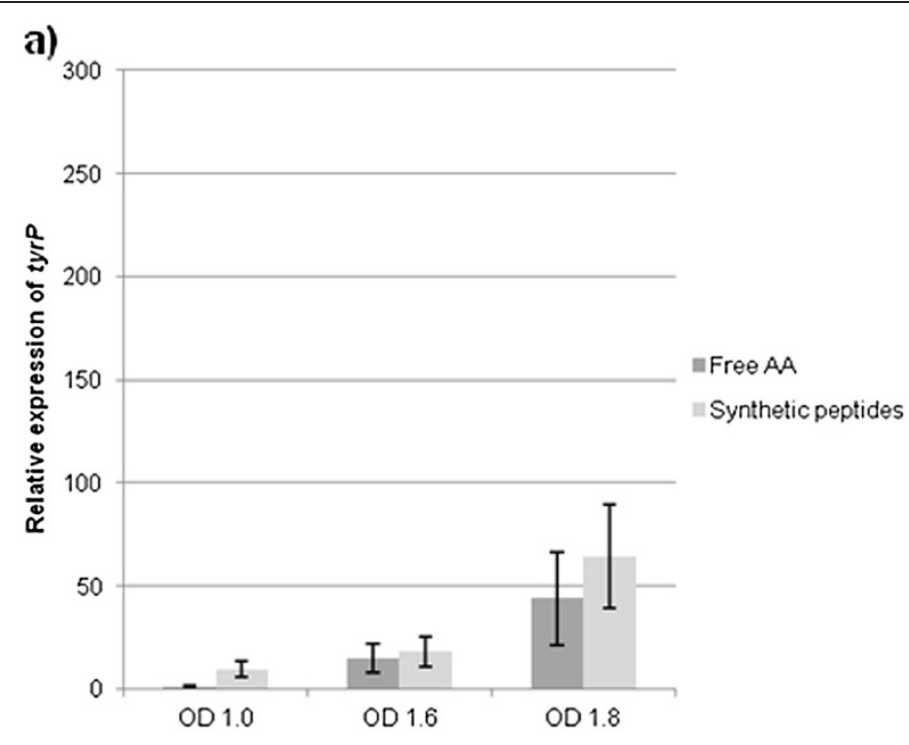

b)

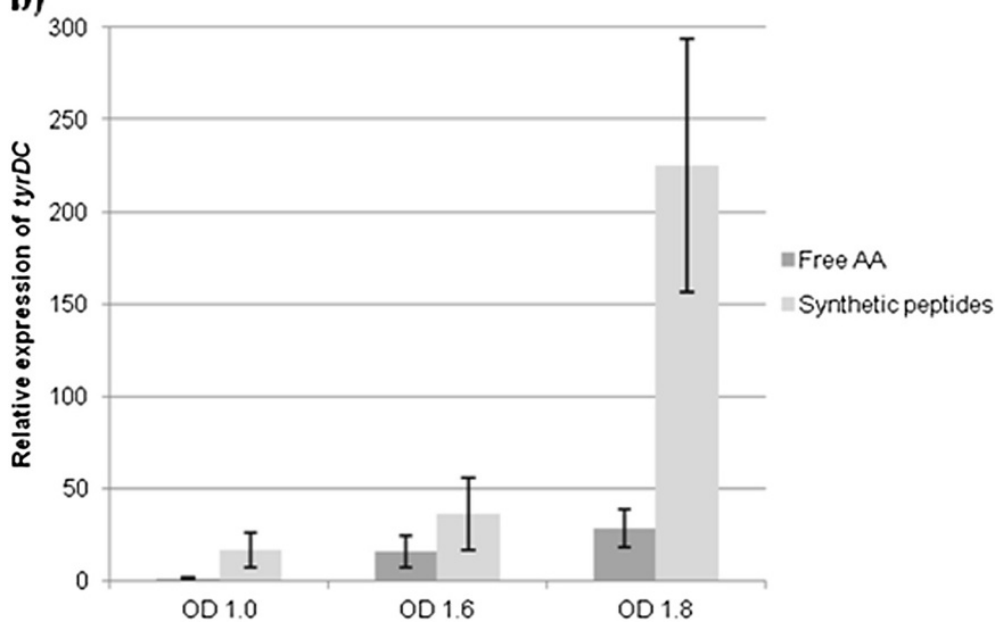

Figure 3 Relative expression of: a) the tyramine transporter tyrP and b) the tyrosine decarboxylase tyrDC in L. plantarum IR BL0076 grown with free tyrosine or tyrosine-containing peptides. Expression was measured at three different $\mathrm{OD}_{600 \mathrm{~nm}}$. Each value is the mean +SD of three independent experiments. The difference between the values labeled a are significantly different, likewise those labeled b (ANOVA, $p<0.05$ ). Significant differences between Free AA (medium 1) and Synthetic peptides (medium 2) media for each OD are indicated with an asterix.

to enhance the performance of yeasts and lactic acid bacteria, and to improve wine quality. This is why the influence of nitrogen sources on biogenic amines production has been extensively studied. Indeed, the presence of fine yeasts lees increase BA production, because of the wide range of nitrogen-containing precursors released [4]. Because nitrogen, and especially yeastassimilable nitrogen, is the limiting factor for yeast development, musts are sometimes supplemented with nitrogen sources [24,51]. Thus, nutritive supplements, for example yeast autolysates containing amino acids and proteins, are added to must to activate alcoholic fermentation. It has been shown that after malolactic fermentation, the concentration of biogenic amines is higher in wine produced with supplemented than unsupplemented must [52]. Therefore, as LAB are able to produce biogenic amines both from amino acids and directly from peptides, enological practices favoring the development of alcoholic fermentation and malolactic fermentation have to be carefully monitored.

\section{Methods}

\section{Bacterial strain and growth conditions}

Lactobacillus plantarum IR BL0076 (provided by InterRhône, France) was isolated from wines of the Rhône Valley during aging. This strain produces tyramine. 


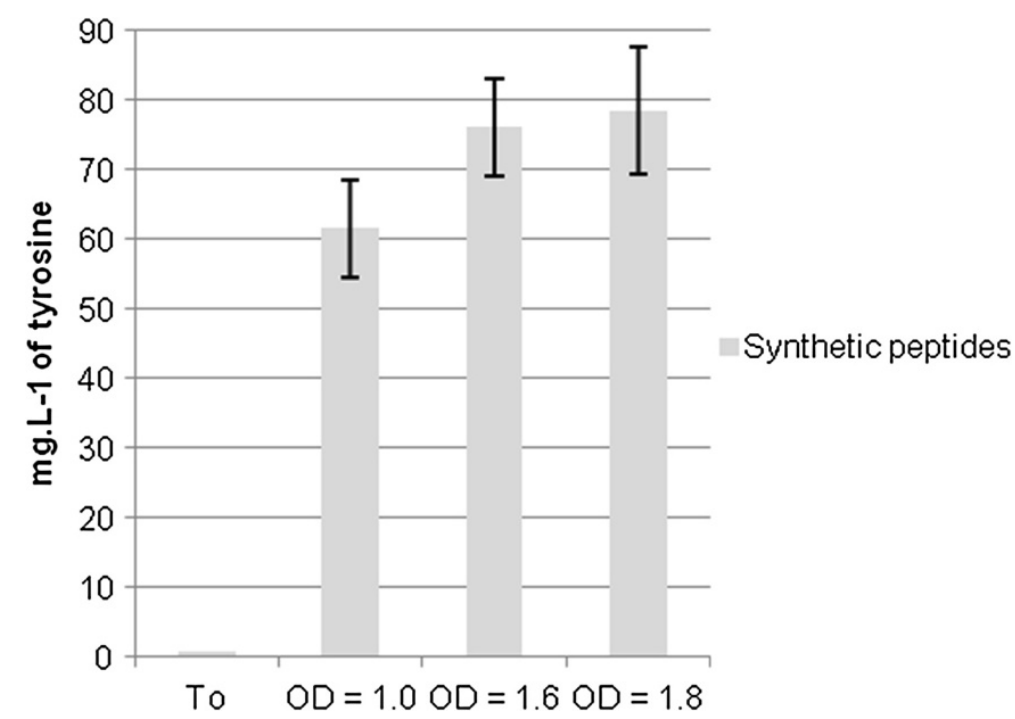

Figure 4 Tyrosine concentration in the supernatants of the culture media containing synthetic peptides. To corresponds to the tyrosine concentration in the medium before inoculation with L. plantarum IR BL0076. Each value is the mean \pm SD of three independent experiments.

\section{Study of the tdc pathway of $L$. plantarum}

Primers tyrSa and nhaCa (Table 2) were used to sequence the $\operatorname{tyr} D C$ and $\operatorname{tyr} P$ genes. These primers were designed according to the sequence of the $t d c$ locus of $L$. brevis (accession number [GenBank: EU195891]).

L. plantarum IR BL0076 was inoculated at $\mathrm{OD}_{600 \mathrm{~nm}}=$ 0.025 in a nitrogen-free synthetic medium containing the following components: 5 g. $\mathrm{L}^{-1}$ glucose, 3.5 g. $\mathrm{L}^{-1}$ fructose, 10 g.L $\mathrm{L}^{-1}$ D,L- malic acid, 0.6 g.L $\mathrm{L}^{-1} \mathrm{KH}_{2} \mathrm{PO}_{4}$, 0.45 g.L. $\mathrm{L}^{-1} \mathrm{KCl}, \quad 0.13$ g.L. $\mathrm{L}^{-1} \quad \mathrm{CaCl}_{2}, \quad 2 \mathrm{H}_{2} \mathrm{O}, \quad 0.13$ g.L. $\mathrm{L}^{-1}$ $\mathrm{MgSO}_{4}, 7 \mathrm{H}_{2} \mathrm{O}, 3 \mathrm{mg} . \mathrm{L}^{-1} \mathrm{MnSO}_{4}, \mathrm{H}_{2} \mathrm{O}$, and $1 \mathrm{~mL} . \mathrm{L}^{-1}$ Tween 80, at pH 5 .

Amino acids were added one by one as nitrogen sources according to Terrade et al. [53]. This medium corresponds to the first culture condition where amino acids are free and contains $1.6 \mathrm{mM}$ of tyrosine.
Otherwise, in a second condition, tyrosine was replaced by $1.6 \mathrm{mM}$ of a mix of synthetic peptides containing tyrosine: Gly-Gly-Tyr-Arg, Tyr-Ala and Gly-Leu-Tyr purchased from Sigma-Aldrich (Saint Quentin Fallavier, France). Aliquots of $50 \mathrm{~mL}$ of culture were harvested after various times of the growth and centrifuged for $10 \mathrm{~min}$ at $6,000 \mathrm{rpm}$. The pellets were stocked at $-20^{\circ} \mathrm{C}$ until RNA extraction. A $1 \mathrm{~mL}$ sample of each supernatant was derivatized and analyzed by HPLC to assay biogenic amines and amino acids. The rest of the supernatant was stored at $-20^{\circ} \mathrm{C}$.

\section{Amino acid and biogenic amine analysis by HPLC}

Free AA and BA were analyzed by HPLC using the method described by Gomez-Alonso et al. [47]. The derivatization reaction was performed by adding $1.75 \mathrm{~mL}$ of

Table 2 Oligonucleotides used in this study

\begin{tabular}{|c|c|c|c|c|}
\hline Primer name & Gene function & Primer sequence & Product size (bp) & Source \\
\hline tyrSa & tyrosil-tRNA synthetase & GTACGGATACGGACGCACAA & 3815 & This work \\
\hline nhaCa & antiporter $\mathrm{Na}+/ \mathrm{H}+$ & CCTAGTGAAAAATGGACAGC & & \\
\hline tdcf & tyrosine decarboxylase & CAAATGGAAGAAGAAGTTGG & 1761 & [55] \\
\hline tyrPLpR & tyrosine/tyramine transporter & TAGTTCCCAACTCACCAGAAA & & This work \\
\hline $\mathrm{tdcBF}$ & tyrosine decarboxylase & GCCTTAGAAAGTATTATTCG & 118 & This work \\
\hline $\operatorname{tdcBR}$ & & AGCGACAATCTTATCAATGC & & \\
\hline tyrPLpF & tyrosine/tyramine transporter & TATGATTGCCACCGTTCGTTC & 128 & This work \\
\hline tyrPLpR & & TAGTTCCCAACTCACCAGAAA & & \\
\hline IdhD (Forward primer) & dehydrogenase & ATCGGTACTGGTCGGATTGG & 123 & {$[56]$} \\
\hline IdhD (Reverse primer) & & GGTGTCAACGTACATGCCTTC & & \\
\hline gyrA (Forward primer) & gyrase & GTTCGTCTCATGCGGTTAGG & 85 & [56] \\
\hline gyrA (Reverse primer) & & AACTGGTGCCTCAGTCGTTG & & \\
\hline
\end{tabular}


borate buffer $\mathrm{pH} 9,1 \mathrm{~mL}$ of methanol, $40 \mu \mathrm{L}$ of internal standard (2,4,6-trimethylphenethylamine hydrochloride, $2 \mathrm{mg} \cdot \mathrm{mL}^{-1}$ ), and $30 \mu \mathrm{L}$ of DEEMM (diethyl ethoxymethylenemalonate) to $1 \mathrm{~mL}$ of target sample. The samples were placed for $30 \mathrm{~min}$ in an ultrasound bath, then heated to $70^{\circ} \mathrm{C}$ for $2 \mathrm{~h}$ to allow complete degradation of excess DEEMM and reagent byproducts. The analyses were performed on a Varian HPLC (Varian Inc., Walnut Creek, CA) using an Alltech (Grace, Templemars, France) HPLC column (C18-HL), particle size $5 \mu \mathrm{m}(250 \mathrm{~mm} \times 4.6 \mathrm{~mm})$, maintained at $16^{\circ} \mathrm{C}$, with a binary gradient. Phase A was modified with $10 \mathrm{mM}$ ammonium acetate $\mathrm{pH} 5.8$ to allow the identification of AA and BA by mass spectrometry. The mobile phase, phase $B$, was 80:20 mixture of acetonitrile and methanol and the flow rate a constant 0.9 mL. $\mathrm{min}^{-1}$.

\section{HPLC-MS conditions}

LC-MS/MS analyses were performed on a ThermoFinnigan TSQ Quantum triple quadrupole mass spectrometer equipped with a standard electrospray ionization source fitted with a $100 \mu \mathrm{m}$ i.d. H-ESI needle. HPLC was performed using an Accela $^{\mathrm{TM}}$ LC pump from ThermoFinnigan (San Jose, CA, USA) equipped with an Accela autosampler (for HPLC conditions, see paragraph above). The flow from LC was split using an analytical fixed flow splitter (split ratio=1:10, post-column) from Analytical Scientific Instruments (El Sobrante, CA, USA). The data were processed using Xcalibur software (ThermoFinnigan).

The source spray head was oriented at an angle of $90^{\circ} \mathrm{C}$ orthogonal to the ion-transfer tube. The mass spectrometer was operated in the negative ion mode in the range of $m / z 90-900$ with a scan time of $1 \mathrm{~s}$. Nitrogen was used as the sheath gas, ion sweep gas and the auxiliary gas, at 30, 5 and 30 (arbitrary units), respectively. The spray voltage was $3 \mathrm{kV}$, the tube lens offset $-132 \mathrm{~V}$ and the skimmer offset $5 \mathrm{~V}$. The ion transfer capillary temperature and vaporizer temperature were 250 and $300^{\circ} \mathrm{C}$ respectively. All the amines give a $\mathrm{m} / z$ signals that correspond to the structure $[M-\mathrm{H}]^{-}$.

Each amine was injected at 1 to $10 \mu \mathrm{g} \cdot \mathrm{mL}^{-1}$ for mass characterization. Collision-induced dissociation (CID) was performed from 20 to $30 \mathrm{eV}$ under 1.5 mTor of argon.

\section{PCR amplification}

L. plantarum identification was performed by $16 \mathrm{~S}$ ribosomal RNA gene sequencing and multiplex PCR using recA gene-derived primers [43]. Chromosomal DNA from L. plantarum was extracted using the Wizard Genomic Kit (Promega, Charbonnières les Bains, France). Amplification and sequencing of the $16 \mathrm{~S}$ gene was performed using the High Fidelity Taq polymerase (Roche,
Meylan, France) and the universal primers BSF8 and BSR1541 [54]. Amplification conditions were $94^{\circ} \mathrm{C}$ for $2 \mathrm{~min}, 10$ cycles of $94^{\circ} \mathrm{C}$ for $15 \mathrm{~s}, 52^{\circ} \mathrm{C}$ for $30 \mathrm{~s}$, and $72^{\circ} \mathrm{C}$ for $1 \mathrm{~min} 30 \mathrm{~s}$, followed by 20 cycles with an additional time of $5 \mathrm{~s}$ for each elongation reaction and a final extension at $72^{\circ} \mathrm{C}$ for $10 \mathrm{~min}$. Multiplex PCR protocol developed by Torriani et al. [43] was performed with Go Taq polymerase (Promega, Charbonnières les Bains, France) and was modified for dNTP concentration ( $0.2 \mathrm{mM}$ inside of $12 \mu \mathrm{M})$ and for annealing time (20 s inside of $10 \mathrm{~s})$. The L. plantarum IR BL0076 tyrDC and tyrP genes were amplified by PCR using High Fidelity Taq polymerase (Roche, Meylan, France) and primers tyrSa and nhaCa based on the tyrS and $n h a C$ sequences which flanked tyrDC and tyrP genes of L. brevis NS77 [GenBank : EU195891]. Amplification was performed in a final volume of $50 \mu \mathrm{L}$, with $5 \mu \mathrm{L}$ of Expand High Fidelity buffer (Roche, Meylan, France), $1 \mu \mathrm{L}$ of $10 \mathrm{mM}$ dNTP mix (Fermentas, Villebon sur Yvette, France), $1 \mu \mathrm{L}$ of each primer at $20 \mu \mathrm{M}, 2.6 \mathrm{U}$ of Expand High Fidelity enzyme mix (Roche, Meylan, France), and $1 \mu \mathrm{L}$ of extract DNA. The amplification program was applied in a Bio-Rad thermocycler following the manufacturer's instructions for long fragments. PCR fragments were purified using the GenElute PCR purification kit (Sigma, Saint Quentin Fallavier, France) and sent to Benckman Coulter Genomics (United kingdom) for sequencing.

\section{Total RNA extraction and RT-PCR}

L. plantarum RNA was extracted after various periods of growth in media 1 and 2 (when the cultures reached at $\mathrm{OD}_{600 \mathrm{~nm}}=1.1,1.6$ and 1.8). Aliquots of $25 \mathrm{~mL}$ of culture were harvested, and the cells pelleted and washed with $10 \mathrm{~mL}$ of Tris $\mathrm{HCl} 10 \mathrm{mM} \mathrm{pH} \mathrm{8.} \mathrm{The} \mathrm{cells} \mathrm{were}$ then broken in $1 \mathrm{~mL}$ of Tri-Reagent (Sigma, Saint Quentin Fallavier, France) in a screw cap tube containing $200 \mathrm{mg}$ of beads $(100 \mu \mathrm{m})$ in a Precellys 24 ultrasound device (Ozyme, Saint Quentin en Yvelines, France) programmed as follows: $6500,3 \times 30 \mathrm{~s}$, twice. Cell fragments were pelleted by centrifugation $\left(12,000 \times g, 10 \mathrm{~min}, 4^{\circ} \mathrm{C}\right)$ and the supernatant was transferred to an Eppendorf tube and $200 \mu \mathrm{L}$ of chloroform was added. The tubes were then vortexed for $15 \mathrm{~s}$ and incubated at room temperature for $15 \mathrm{~min}$. The samples were centrifuged at $12,000 \times g$ for $15 \mathrm{~min}$ at $4^{\circ} \mathrm{C}$. The upper layer was transferred to a new Eppendorf tube and $500 \mu \mathrm{L}$ of isopropanol was added. The samples were mixed gently, incubated at room temperature for $15 \mathrm{~min}$ and centrifued at $12,000 \times g$ for $10 \mathrm{~min}$ at $4^{\circ} \mathrm{C}$. The supernatant was removed and the pellet was washed with $75 \%$ ethanol. The tubes were centrifuged at $12,000 \times g$ for $10 \mathrm{~min}$ at $4^{\circ} \mathrm{C}$ and the resulting RNA pellets were dried and resuspended in $30 \mu \mathrm{L}$ of RNase-free water (Fermentas, Villebon sur Yvette, France). These RNA samples were 
then purified with the RNeasy MiniKit (Qiagen, Courtaboeuf, France) and checked for yield and quality by measuring the OD ratio at 260, 280 and $320 \mathrm{~nm}$ in a BioPhotometer (Eppendorf, Le Pecq, France).

Aliquots of $2 \mu \mathrm{g}$ of RNA were treated with $1 \mathrm{U}$ of DNase I (Fermentas, Villebon sur Yvette, France) to eliminate residual DNA and used for PCR. A control PCR with irrelevant primers BSF8 and BSR1541 was carried out with the RNA to check the absence of any amplification. Total cDNA was then synthesized with iScript cDNA Synthesis Kit (BioRad, Marnes la Coquette, France) following the manufacturer's recommendations. RT-PCR experiments were performed on cDNA with primers tdcf [55] and tyrPLpR (Table 2), and High Fidelity Taq polymerase (Roche, Meylan, France).

\section{Quantification of gene expression by real time quantitative PCR}

Reverse transcription-quantitative real-time PCR (RT qPCR), with iQ SYBR green supermix (BioRad, Marnes la Coquette, France) and the BioRad CFX96 Real-Time System was used for gene expression analysis.

First, primer specificity and efficacy were checked by using 10-fold serial dilutions of L. plantarum IR BL0076 DNA. The melting curves obtained showed the absence of primer dimers, and the calibration curves, for each pair of primers, showed a slope between $86.8 \%$ and 96.2\%, and a regression coefficient between 0.997 and 1 . Total cDNA was serially diluted ( 1 in 4 ), and a $5 \mu \mathrm{L}$ aliquot was added to each well containing $20 \mu \mathrm{L}$ of a mix of $12.5 \mu \mathrm{L}$ of SYBR green supermix, $1 \mu \mathrm{L}$ of each primer at 7 pmol. $\mu \mathrm{L}^{-1}$ and $5.5 \mu \mathrm{L}$ of RNase-free water. The specific primers used to amplify particular cDNA sequences are given in Table 2. $l d h D$ and gyrA are housekeeping genes used to normalize RNA expression data. These genes were used by Duary et al. [56] as the most stably expressed genes for RT-qPCR experiments in L. plantarum. Moreover ldhD gene was validated in L. plantarum for RT-qPCR experiments by Fiocco et al. [57]. Each run included a negative control with $5 \mu \mathrm{L}$ of RNase-free water instead of cDNA, and a positive control using L. plantarum IR BL0076 DNA. The amplification program was as follows: $98^{\circ} \mathrm{C}, 30 \mathrm{~s}$ and 40 cycles of $95^{\circ} \mathrm{C}, 10 \mathrm{~s} ; 60^{\circ} \mathrm{C}, 30 \mathrm{~s}$. For each experiment, the condition "culture medium 1 (with free tyrosine), $\mathrm{OD}_{600 \mathrm{~nm}}=$ 1.0" was used to calibrate the expression data. The analyses were performed on RNA extracted and purified from three independent cultures for each growth condition.

\section{Statistical analysis}

R: A language and environment for statistical computing (R Development Core Team (2008); R Foundation for Statistical Computing, Vienna, Austria) was used for statistical analysis. Results were analyzed by one-way ANOVA and considered significant at $\mathrm{p}<0.05$.

\section{Sequence analysis and accession number}

The $16 \mathrm{~S}$ ribosomal gene sequence was analyzed using the Blast server for identification of Procaryotes (http:// bioinfo.unice.fr/blast/). Sequence similarity searches were carried out using Basic Local Aligment Search Tool (BLAST) on the JGI website (http://www.jgi.doe.gov/). Multiple alignments were obtained using the CLUSTALW2 program on the EMBL-EBI web site (http://www. ebi.ac.uk/). The tool TreeTop of GeneBee Molecular Biology Server was used for phylogenetic tree construction (http://www.genebee.msu.su/genebee.html). The partial nucleotide sequence of the $t d c$ locus and the $16 \mathrm{~S}$ ribosomal DNA sequence of L. plantarum IR BL0076 are available in the GenBank database under the accession number [GenBank : JQ040309] and [GenBank : JX025073] respectively.

\section{Additional file}

Additional file 1: Sequence alignment of TyrDC from L. brevis and L. plantarum.

\section{Abbreviations}

BA: Biogenic amines; AA: Amino acids; LAB: Lactic acid bacteria; RPHPLC: Reverse-phase high-performance liquid chromatography; MLF: Malolactic fermentation; Rt-qPCR: Real time quantitative polymerase chain reaction; LC-MS/MS: Liquid chromatography-mass spectrometry/Mass spectrometry.

\section{Competing interests}

This work was supported by the European Community's Seventh Framework Program, grant agreement no. 211441-BIAMFOOD.

\section{Authors' contributions}

MB carried out all the analysis, and drafted the manuscript. CG participated in the design of the study, coordination and helped to draft the manuscript participated in the sequence analysis. AR and SW participated in the design of the study, especially the RT-QPCR experiments, coordination and helped to draft the manuscript. HA participated in the design of the study, coordinated all the work and helped to draft the manuscript. All authors read and approved the final manuscript.

\section{Acknowledgements}

We are grateful to Benoît Bach from Inter-Rhône for providing the Lactobacillus plantarum strain IR BL0076. Mass spectrometry analyses were performed by the Lipides-Arômes platform, UMR FLAVIC, INRA Dijon.

Received: 20 March 2012 Accepted: 31 August 2012

Published: 11 September 2012

\section{References}

1. Silla Santos MH: Biogenic amines: their importance in foods. Int J Food Microbiol 1996, 29:213-231.

2. Bauza T, Blaise A, Teissedre PL, Cabanis JC, Kanny G, Moneret-Vautrin DA, Daumas F: Les amines biogènes du vin: metabolisme et toxicité. Bulletin de I'OIV 1995, 68:42-67.

3. Hannington E: Preliminary report on tyramine headache. Br Med J 1967, 2:550-551

4. Marques AP, Leitao MC, San Romao MV: Biogenic amines in wines: influence of oenological factors. Food Chem 2008, 107:853-860. 
5. Konings WN, Lolkema JS, Bolhuis H, Van Veen HW, Poolman B, Driessen AJM: The role of transport processes in survival of lactic acid bacteria. Antonie Leeuwenhoek 1997, 71:117-128.

6. Molenaar D, Bosscher JS, Brink BT, Driessen AJM, Konings WN: Generation of a proton motive force by histidine decarboxylation and electrogenic histidine/histamine antiport in lactobacillus buchneri. J Bacteriol 1993, 175:2864-2870.

7. Wolken WAM, Lucas PM, Lonvaud-Funel A, Lolkema JS: The mechanism of the tyrosine transporter TyrP supports a proton motive tyrosine decarboxylation pathway in lactobacillus brevis. J Bacteriol 2006, 188:2198-2206

8. Lonvaud-Funel A, Joyeux A: Histamine production by wine lactic acid bacteria: isolation of a histamine-producing strain of leuconostoc oenos. J Appl Microbiol 1994, 77:401-407.

9. Marcobal AB, De Las Rivas B, Moreno-Arribas MV, Munoz R: Identification of the ornithine decarboxylase gene in the putrescine-producer oenococcus oeni BIFI-83. FEMS Microbiol Lett 2004, 239:213-220.

10. Moreno-Arribas V, Torlois S, Joyeux A, Bertrand A, Lonvaud-funel A: Isolation, properties and behaviour of tyramine-producing lactic acid bacteria from wine. J App/ Microbiol 2000, 88:584-593.

11. Guerrini S, Mangani S, Granchi L, Vincenzini M: Biogenic amine production by oenococcus oeni. Curr Microbiol 2002, 44:374-378.

12. Coton $E$, Coton M: Evidence of horizontal transfer as origin of strain to strain variation of the tyramine production trait in lactobacillus brevis. Food Microbiol 2009, 26:52-57.

13. Connil N, Le Breton $Y$, Dousset $X$, Auffray $Y$, Rincé $A$, Prévost $H$ : Identification of the enterococcus faecalis tyrosine decarboxylase operon involved in tyramine production. Appl Environ Microbiol 2002, 68:3537-3544

14. Fernández M, Linares DM, Alvarez MA: Sequencing of the tyrosine decarboxylase cluster of lactococcus lactis IPLA 655 and the development of a PCR method for detecting tyrosine decarboxylating lactic acid bacteria. J Food Prot 2004, 67:2521-2529.

15. Lucas $\mathrm{P}$, Landete J, Coton M, Coton E, Lonvaud-Funel A: The tyrosine decarboxylase operon of lactobacillus brevis IOEB 9809: characterization and conservation in tyramine-producing bacteria. FEMS Microbiol Lett 2003, 229:65-71

16. Gardini F, Zaccarelli A, Belletti N, Faustini F, Cavazza A, Martuscelli M, Mastrocola D, Suzzi G: Factors influencing biogenic amine production by a strain of oenoccocus oeni in a model system. Food Control 2005, 16:609-616

17. Hernandez-Orte P, Pena-Gallego A, Ibarz MJ, Cacho J, Ferreira V: Determination of the biogenic amines in musts and wines before and after malolactic fermentation using 6-aminoquinolyl- $\mathrm{N}$ hydroxysuccinimidyl carbamate as the derivatizing agent. J Chrom A 2006, 1129:160-164

18. Herbert $\mathrm{P}$, Cabrita MJ, Ratola N, Laureano O, Alves A: Free amino acids and biogenic amines in wines and musts from the Alentejo region. Evolution of amines during alcoholic fermentation and relationship with variety, sub-region and vintage. J Food Eng 2005, 66:315-322.

19. Lonvaud-Funel A: Biogenic amines in wines: role of lactic acid bacteria. FEMS Microbiol Lett 2001, 199:9-13.

20. Solieri L, Genova F, De Paola M, Giudici P: Characterization and technological properties of oenococcus oeni strains from wine spontaneous malolactic fermentations: a framework for selection of new starter cultures. J Appl Microbiol 2010, 108:285-298.

21. Pessione E, Mazzoli R, Giuffrida MG, Lamberti C, Garcia-Moruno E, Barello C, Conti A, Giunta C: A proteomic approach to studying biogenic amine producing lactic acid bacteria. Proteomics 2005, 5:687-689.

22. Soufleros EH, Bouloumpasi E, Zotou A, Loukou Z: Determination of biogenic amines in Greek wines by HPLC and ultraviolet detection after dansylation and examination of factors affecting their presence and concentration. Food Chem 2007, 101:704-716.

23. Pereira V, Pontes M, Camara JS, Marques JC: Simultaneous analysis of free amino acids and biogenic amines in honey and wine samples using in loop orthophthalaldeyde derivatization procedure. J Chrom A 2008, 1189:435-443

24. Bach B, Colas S, Massini L, Barnavon L, Vuchot P: Effect of nitrogen addition during alcoholic fermentation on the final content of biogenic amines in wine. Ann Microbiol 2010, 61:185-190.

25. Babayan TL, Bezrukov MG: Autolysis in yeasts. Acta Biotechnol 1985, 2:129-136.
26. Alexandre H, Heintz D, Chassagne D, Guilloux-Benatier M, Charpentier C, Feuillat M: Protease A activity and nitrogen fractions released during alcoholic fermentation and autolysis in enological conditions. J Ind Microbiol Biot 2001, 26:235-240.

27. Bozdogan A, Canbas A: Influence of yeast strain, immobilisation and ageing time on the changes of free amino acids and amino acids in peptides in bottle-fermented sparkling wines obtained from vitis vinifera cv. Emir. Int J of Food Sci Tech 2011, 46:1113-1121.

28. Feuillat M, Brillant $G$, Rochard J: Mise en évidence d'une production de proteases exocellulaires par les levures au cours de la fermentation alcoolique du moût de raisin. Connais Vigne Vin 1980, 14:37-52.

29. de Nadra MC M, Farias ME, Moreno-Arribas MV, Pueyo E, Polo MC: Proteolytic activity of leuconostoc oenos. Effect on proteins and polypeptides from white wine. FEMS Microbiol Lett 1997, 150:135-139.

30. de Manca Nadra MC, Farias ME, Moreno-Arribas MV, Pueyo E, Polo MC: A proteolytic effect of oenococcus oeni on the nitrogenous macromolecular fraction of red wine. FEMS Microbiol Lett 1999, 174:41-47.

31. Folio P, Ritt JF, Alexandre H, Remize F: Characterization of EprA, a major extracellular protein of oenococcus oeni with protease activity. Int J Food Microbiol 2008, 127:26-31.

32. Leitao MC, Teixeira HC, Barreto Crespo MT, San Romao MV: Biogenic amines occurrence in wine. Amino acid decarboxylase and proteolytic activities expression by oenococcus oeni. J Agric Food Chem 2000, 48:2780-2784.

33. Strahinic I, Kojic M, Tolinacki M, Fira D, Topisirovic L: The presence of prtP proteinase gene in natural isolate lactobacillus plantarum BGSJ3-18. Lett Appl Microbiol 2009, 50:43-49.

34. Kunji ERS, Smid EJ, Plapp R, Poolman B, Konings WN: Di-tripeptides and oligopeptides are taken up via distinct transport mechanisms in lactococcus lactis. J Bacteriol 1993, 175:2052-2059.

35. Fang G, Konings WN, Poolman B: Kinetics and substrate specificity of membrane-reconstituted peptide transporter DtpT of lactococcus lactis. J Bacteriol 2000, 182:2530-2535.

36. Sanz Y, Toldra F, Renault P, Poolman B: Specificity of the second binding protein of the peptide ABC-transporter (Dpp) of lactococcus lactis IL1403. FEMS Microbiol Lett 2003, 227:33-38.

37. Kleerebezem M, Boekhorst J, Van Kranenburg R, Molenaar D, Kuipers OP, Leer R, Tarchini R, Peters SA, Sandbrink HM, Fiers MWEJ, Stiekema W, Klein Lankhorst RM, Bron PA, Hoffer SM, Nierop Groot MN, Kerkhoven R, De Vries M, Ursing B, De Vos WM, Siezen RJ: Complete genome sequence of lactobacillus plantarum WCFS1. PNAS 2003, 100:1990-1995.

38. Varmanen $P$, Vesanto $E$, Steele $J$, Palva A: Characterization and expression of the PepN gene encoding a general aminopeptidase from lactobacillus helveticus. FEMS Microbiol Lett 1994, 124:315-320.

39. Tsakalidou E, Dalezios I, Georgalaki M, Kalantzopoulos G: A comparative study: aminopeptidase activities from lactobacillus delbrueckii ssp. bulgaricus and streptococcus thermophilus. J Dairy Sci 1993, 76:2145-2151.

40. Tan PST, Van Alen-Boerrigter IT, Poolman B, Siezen RJ, De Vos WM, Konings $W N$ : Characterization of the lactococcus lactis pep $N$ gene encoding an aminopeptidase homologous to mammalian aminopeptidase N. FEBS 1992, 306:9-16.

41. Hwang IK, Kaminogawa S, Yamauchi K: Purification and properties of a dipeptidase from streptococcus cremoris. Agric Biol Chem 1981, 45:159-166.

42. Arena ME, Fiocco D, de Manca Nadra MC, Pardo I, Spano G: Characterization of a lactobacillus plantarum strain able to produce tyramine and partial cloning of a putative tyrosine decarboxylase gene. Curr Microbiol 2007, 55:205-210.

43. Torriani S, Felis GE, Dellaglio F: Differentiation of lactobacillus plantarum, $\mathrm{L}$. pentosus, and L. paraplantarum by recA gene sequence analysis and multiplex PCR assay with recA gene-derived primers. Appl Environ Microbiol 2001, 67:3450-3454

44. Teusink B, Van Enckevort FHJ, Francke C, Wiersma A, Wegkamp A, Smid EJ, Siezen RJ: In silico reconstruction of the metabolic pathways of lactobacillus plantarum: comparing predictions of nutrient requirements with those from growth experiments. Appl Environ Microbiol 2005, 71:7253-7262.

45. Pereira Cl, Barreto Crespo MT, San Romao MV: Evidence for proteolytic activity and biogenic amines production in lactobacillus curvatus and $L$. homohiochii. Int J Food Microbiol 2001, 68:211-216. 
46. Kunji ERS, Mierau I, Hagting A, Poolman B, Konings WN: The proteolytic system of lactic acid bacteria. Antonie Leeuwenhoek 1996, 70:187-221.

47. Gomez-Alonso S, Hermosian-Gutearrez I, Garcia-Romero E: Simultaneous HPLC analysis of biogenic amines, amino acids, and ammonium ion as aminoenone derivatives in wine and beer samples. J Agric Food Chem 2007, 55:608-613.

48. Leitao MC, Marques AP, San Romao MV: A survey of biogenic amines in commercial Portuguese wines. Food Control 2005, 16:199-204.

49. Coton M, Fernandez M, Trip H, Ladero V, Mulder NL, Lolkema JS, Alvarez MA, Coton E: Characterization of the tyramine-producing pathway in sporolactobacillus sp P3J. Microbiology 2011, 157:1841-1849.

50. Calles-Enriquez M, Hjort Eriksen B, Skov Andersen P, Rattray FP, Johansen $\mathrm{AH}$, Fernandez M, Ladero V, Alvarez MA: Sequencing and transcriptional analysis of the streptococcus thermophilus histamine biosynthesis gene cluster: factors that affect differential hdcA expression. Appl Environ Microbiol 2010, 76:6231-6238.

51. Bely M, Sablayrolles JM, Barre P: Automatic detection of assimilable nitrogen deficiencies during alcoholic fermentation in oenological conditions. J Ferment Bioeng 1991, 70:246-252.

52. Gonzales Marco A, Moreno NJ, Ancin Azpilicueta C: Influence of addition of yeast autolysate on the formation of amines in wine. I Sci Food Agric 2006, 86:2221-2227.

53. Terrade N, Noel R, Couillaud R, De Mira Orduna R: A new chemically defined medium for wine lactic acid bacteria. Food Res Int 2009, 42:363-367.

54. Wilmotte A, Van der Auwera G, De Wachter R: Structure of the $16 \mathrm{~S}$ ribosomal RNA of the thermophilic cynobacterium chlorogloeopsis HTF (dMastigocladus laminosus HTFT) strain PCC7518, and phylogenetic analysis. FEBS Lett 1993, 317:96-100.

55. Nannelli F, Claisse O, Gindreau E, De Revel G, Lonvaud-Funel A, Lucas PM: Determination of lactic acid bacteria producing biogenic amines in wine by quantitative PCR methods. Lett Appl Microbiol 2008, 47:594-599.

56. Duary RK, Batish VK, Grover S: Expression of the atpD gene in probiotic lactobacillus plantarum strains under in vitro acidic conditions using RTqPCR. Res Microbiol 2010, 161:399-405.

57. Fiocco D, Crisetti E, Capozzi V, Spano G: Validation of an internal control gene to apply reverse transcription quantitative PCR to study heat, cold and ethanol stresses in lactobacillus plantarum. World J Microbiol Biotechnol 2008, 24:899-902.

doi:10.1186/1471-2180-12-199

Cite this article as: Bonnin-Jusserand et al: Tyrosine-containing peptides are precursors of tyramine produced by Lactobacillus plantarum strain IR BL0076 isolated from wine. BMC Microbiology 2012 12:199.

\section{Submit your next manuscript to BioMed Central and take full advantage of:}

- Convenient online submission

- Thorough peer review

- No space constraints or color figure charges

- Immediate publication on acceptance

- Inclusion in PubMed, CAS, Scopus and Google Scholar

- Research which is freely available for redistribution

Submit your manuscript at www.biomedcentral.com/submit
Biomed Central 